\title{
Fatigue behaviour of thin coated Al 7075 alloy with low temperature PVD coatings
}

\author{
Sergio Baragetti ${ }^{1,2, a}$, Riccardo Gerosa ${ }^{3, b}$ and Francesco Villa ${ }^{1, c}$ \\ ${ }^{1}$ Department of Engineering, University of Bergamo, Viale Marconi 5, Dalmine 24044, Italy \\ ${ }^{2}$ GITT - Centre on Innovation Management and Technology Transfer, University of Bergamo, Via \\ Salvecchio 19, Bergamo 24129, Italy \\ ${ }^{3}$ Politecnico di Milano, Polo territoriale di Lecco, Via Marco D'Oggiono 18/A, 23900 Lecco, Italy \\ a sergio.baragetti@unibg.it, b ${ }^{b}$ riccardo.gerosa@polimi.it, c francesco.villa@unibg.it
}

Keywords: 7075-T6, WC/C and DLC coatings, rotating bending fatigue, step loading technique.

\begin{abstract}
T6 is one of the most performing aluminium alloys, considering its mechanical properties and good fatigue behaviour. In this work the influence of $\mathrm{WC} / \mathrm{C}$ and DLC PVD coatings on the fatigue behaviour was investigated by rotating bending tests at $2 \cdot 10^{5}$ cycles. The fatigue behaviour of polished and untreated specimens was considered as reference. In order to decouple the effect of the deposition temperature from the coating one, some uncoated specimens were submitted to the thermal cycles of the $\mathrm{WC} / \mathrm{C}$ and DLC processes and then tested under fatigue loading. Fatigue life was determined using a step-loading technique. SEM micrographs of the fracture surfaces were taken in order to characterize the fatigue mechanisms of coated and uncoated specimens.
\end{abstract}

\section{Introduction}

The use of Physical Vapour Deposition (PVD) coatings to improve the fatigue performances of mechanical components has become a point of crucial interest. Different studies have shown an increase of the fatigue strength of PVD coated steels, due to the beneficial effects of high residual compression stresses [1-5]. Other investigations have been carried out on coated light alloys [5-10], showing both beneficial and detrimental results, depending on the material, the coating, and the process temperature. In the present work, the rotating bending fatigue behaviour of 7075-T6 aluminium uncoated and PVD coated specimens was investigated at $2 \cdot 10^{5}$ cycles. In order to avoid excessive modifications of the microstructural properties, low temperature $\left(180^{\circ} \mathrm{C}\right.$, from [11]) PVD coatings, $\mathrm{WC} / \mathrm{C}$ and $\mathrm{DLC}$, were selected. The influence of the deposition temperature has been investigated reproducing the process thermal cycle on uncoated samples, named as $\mathrm{WC} / \mathrm{C}$ and asDLC respectively; this will be helpful to clarify the actual influence of the coating on the fatigue performances of the considered alloy.

\section{Experimental Setup}

The hourglass specimens were machined and fatigue tested from commercial 7075-T6 bars, following ISO requirements [12], at the Structural Mechanics Laboratory of the University of Bergamo. Further analyses, such as tensile and hardness tests and roughness measurements, were carried out at the metallurgy laboratory of the Politecnico di Milano - Polo territoriale di Lecco. Five sets of samples were prepared: the first one was composed of untreated and polished specimens, to be used as a reference for the fatigue limit. The polishing was obtained using grinding papers and $3 \mu \mathrm{m}$ diamond paste. Two sets of specimens were coated with $\mathrm{WC} / \mathrm{C}$ and DLC treatments respectively. The surface was polished prior to coating, using grinding papers up to 1200 grit, according to the PVD treatment specifications [11]. Two additional sets were prepared submitting the specimens to the $\mathrm{WC} / \mathrm{C}$ and $\mathrm{DLC}$ deposition thermal cycles, and were indicated respectively with asWC/C and asDLC. The surface finishing was carried out until $3 \mu \mathrm{m}$ diamond paste. The chemical composition of the considered alloy is reported in table 1. 
Table 1. Chemical composition of the considered alloy.

\begin{tabular}{ccccccccc}
\hline Si [\%] & Fe [\%] & Cu [\%] & Mn [\%] & Mg [\%] & Zn [\%] & Cr [\%] & Ti [\%] & Al [\%] \\
\hline 0.25 & 0.32 & 1.75 & 0.20 & 2.55 & 5.60 & 0.22 & 0.12 & Bal. \\
\hline
\end{tabular}

The mechanical properties were obtained by means of two tensile tests, using a INSTRON 4507 machine. The average results are reported in table 2. The roughness of uncoated and coated specimens, prior and after coating, were measured near the gage area with a Taylor Hobson Form Talysurf surface profilometer, and reported in table 3 . Hardness tests were performed on the raw material bars, as well as on the uncovered regions of coated and uncoated fatigue specimens, far away from the gage area, using a Wolpert machine, and reported in table 4.

Table 2. Untreated 7075-T6 tensile test results average values.

\begin{tabular}{ccccc}
\hline $\boldsymbol{R}_{\boldsymbol{p}, \boldsymbol{0} \boldsymbol{2}}[\mathrm{MPa}]$ & $\boldsymbol{R}_{\boldsymbol{m}}[\mathrm{MPa}]$ & $\mathbf{A} \%$ & $\mathbf{Z} \%$ & Samples \\
\hline 597 & 658 & 10.2 & 14.0 & 2 \\
\hline
\end{tabular}

Table 3. Roughness measurements averages ( 3 measures per sample) over uncoated and coated specimens

\begin{tabular}{cccccc}
\hline Roughness & Untreated & WC/C & DLC & asWC/C & asDLC \\
\hline $\boldsymbol{R}_{\boldsymbol{a}}[\mu \mathrm{m}]$ & $<0.1$ & 0.3 & 0.2 & $<0.1$ & $<0.1$ \\
\hline $\boldsymbol{R}_{\boldsymbol{a}}[\mu \mathrm{m}]-$ after coating & - & 0.3 & 0.2 & - & - \\
\hline
\end{tabular}

Table 4. Hardness measurements on raw bars and coated and uncoated fatigue specimens

\begin{tabular}{cccc}
\hline Hardness & Average [HV] & Std. Dev. [HV] & $\mathbf{N}^{\circ}$ of measures \\
\hline Raw 7075-T6 bars & 194 & 6 & 8 \\
\hline Fatigue specimens & 184 & 4 & 4 \\
\hline
\end{tabular}

The fatigue limits were determined at $N=2 \cdot 10^{5}$ cycles, using a four points Italsigma X2 TM 412 rotating bending fatigue machine $(R=-1)$, at the Structural Mechanics Laboratory of the University of Bergamo. A step loading technique, already validated for Titanium light alloys [13-14], has been used: the test starts from an initial load value $\sigma_{0}$, and if the specimen runs out, the test is repeated by increasing the load with a $\Delta \sigma$, which has been set to $9 \mathrm{MPa}$ in our tests, until the specimen fails before completing the load block of $N$ cycles. The fatigue limit is the linear interpolation between the last step $\sigma_{f}$, which failed at a $N_{f}<N$ number of cycles, and the previous, not failed step, $\sigma_{p f}$ :

$$
\sigma_{F A f, N}=\sigma_{p f}+\frac{N_{f}}{N}\left(\sigma_{f}-\sigma_{p f}\right)
$$

A confirmation run on a second specimen is then set up, to confirm the fatigue limit.

In order to study in deep the fatigue mechanisms, a SEM investigation was carried out at the CLASD laboratories of Politecnico di Milano.

\section{Results and Discussion}

Fatigue Tests. The fatigue limits obtained for 200'000 cycles are reported in figure 1 for every tested condition. The failure number of cycles $N_{\text {conf }}$ of the confirmation specimen is reported in table 5 , as well as the percentage variation $\Delta \sigma_{\%}$ with respect to the untreated reference value. The results clearly show a sensible deterioration of the fatigue strength of the PVD coated series. Thermal contribution, obtained from the asWC/C and asDLC heated samples, justifies only a fraction of the overall performance drop in the $\mathrm{WC} / \mathrm{C}$ case, while it seems to be the principal driving force for the DLC coating. Saini and Gupta [1] studied WC/C coated SAE8620 carburized steel $R=-1$ fatigue, finding that the coated specimens offered improved fatigue strength in the high cycle fatigue regime (HCF), but they lost their enhanced fatigue performance below $10^{5}$ cycles, due to higher stress levels, which probably caused premature cracking in the coating. 


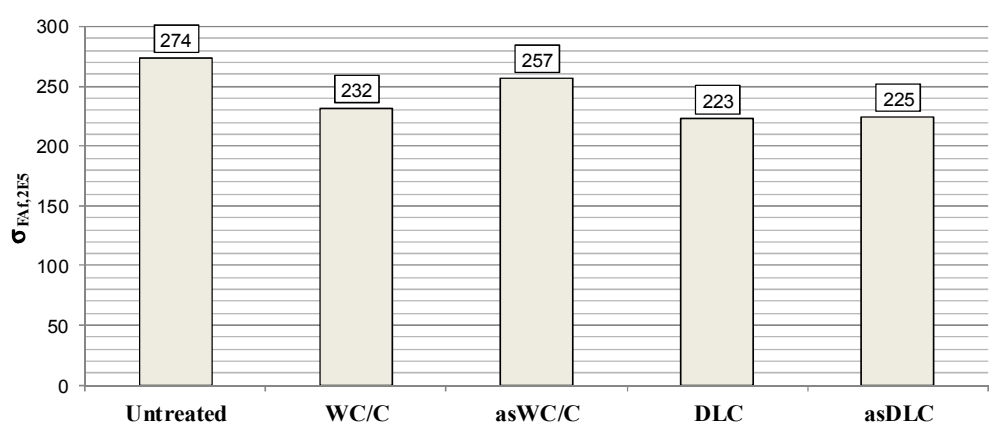

Figure 1. Rotating bending fatigue limit $\sigma_{\mathrm{FAf}, 2 \cdot 10^{5}}$ obtained from the step loading technique specimen.

Table 5. Number of cycles of failure $N_{\text {conf }}$ of the confirmation specimen and $2 \cdot 10^{5}$ cycles fatigue limit performance drop $\Delta \sigma_{\%}$ with respect to the untreated specimen.

\begin{tabular}{cccccc}
\hline Specimen & Untreated & WC/C & asWC/C & DLC & asDLC \\
\hline $\boldsymbol{N}_{\text {conf }}$ & $1233^{\prime} 276$ & $300^{\prime} 636$ & $217^{\prime} 566$ & $119 ' 550$ & $130 ' 516$ \\
\hline$\Delta \boldsymbol{\sigma}_{\%}$ & - & $-15 \%$ & $-6 \%$ & $-19 \%$ & $-18 \%$ \\
\hline
\end{tabular}

A previous work by Baragetti et al. [7], which analysed the rotating bending fatigue behaviour of WC/C and DLC coatings over 2011-T6 aluminium alloy at $N=10^{7}$, confirms an improvement of aluminium alloys fatigue behaviour at HCF. In another work by Baragetti, Gerosa et al. [6], rotating bending fatigue tests were performed on $\mathrm{WC} / \mathrm{C}$ coated and uncoated $7075-\mathrm{T} 6$ specimens at $10^{4}, 10^{5}$ and $10^{6}$ cycles. The extrapolation at $200^{\prime} 000$ cycles from the experimental survey resulted in a beneficial contribution of the coating on the fatigue limits. The different behaviour found in these experimental tests could be related to the superficial finishing of the coated samples: roughness measurements before deposition resulted in $R_{a}$ values of about $0.2-0.3 \mu \mathrm{m}$, near the maximum value requested from Lafer [11]. The surface finishing of the samples tested in [6] was slightly better, i.e. $R_{a}=0.08-0.11 \mu \mathrm{m}$. Regarding the residual stress field induced by the coating deposition, it's difficult to evaluate its influence even if it seems to be more effective in DLC coated samples [1-5]. Nevertheless further investigations are necessary to clarify such point.
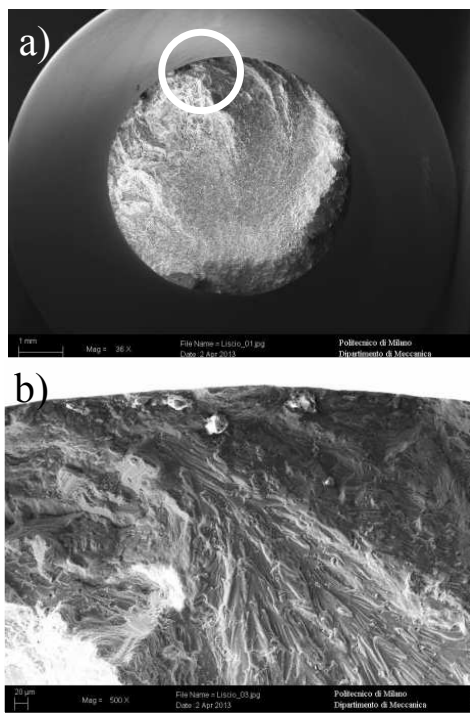

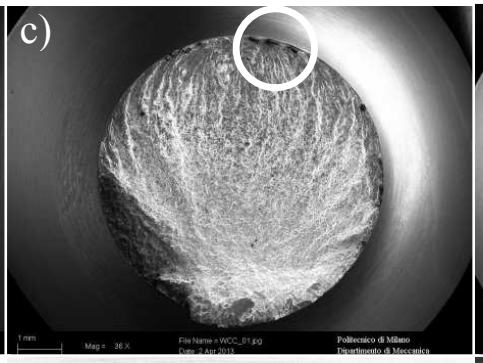

d)

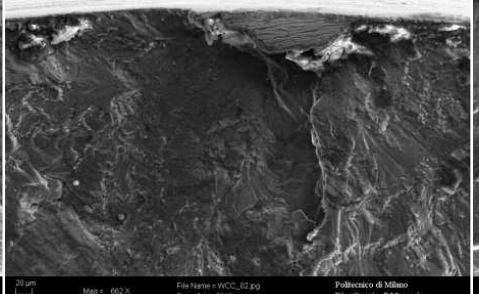

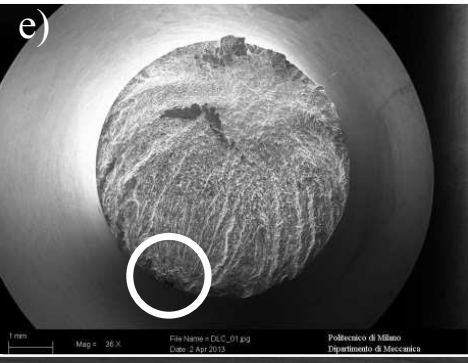

f)

Figure 2. SEM microscopic analysis of different specimens: a) untreated 36x, b) untreated 500x, c) WC/C coated 36x, d) WC/C coated 662x, e) DLC coated 36x and f) DLC coated 1000x. White circles in the upper row identify the magnified regions in the lower row, which show crack initiation regions.

SEM investigation. SEM analysis of the WC/C and DLC specimens fracture surfaces are reported in figure 2. The magnification of two crack initiation sites reveals a brittle behaviour of the coating. Fracture surfaces of the coated specimens show multiple crack initiation sites in the external coating, with respect to the untreated specimen fracture surface. The cracks seem to nucleate in the coating and then they easily propagate through the mild substrate. 


\section{Conclusions}

- Step loading fatigue testing results at $2 \cdot 10^{5}$ cycles showed a reduction of fatigue life of WC/C and DLC coated 7075-T6 samples, with respect to the uncoated samples.

- Thermal contribution was the major contribution to DLC fatigue life reduction, while it accounted only for a fraction of the $\mathrm{WC} / \mathrm{C}$ fatigue strength loss.

- A possible further cause of the preliminary failure of $\mathrm{WC} / \mathrm{C}$ coated specimens, in addition to thermal effects, could be the cracking of the hard and fragile coatings, due to high fatigue stresses in the $2 \cdot 10^{5}$ cycles region and to surface finishing. Such micro cracks can be easily transferred to the mild substrate, causing a premature failure.

\section{Acknowledgements}

The Authors wish to thank Mr. Hassan Karam for the help in the test set up and execution, and Eng. Claudio Carini and Eng. Alessandro Bertè from Lafer SpA, for the execution of the PVD coatings and the valuable technical help.

\section{References}

[1] B.S. Saini, V.K. Gupta: Surf. Coat. Tech. Vol. 205 (2010) ,p. 511

[2] S. Baragetti, G.M. La Vecchia, A. Terranova: Int. J. Fatigue Vol. 23 (2001), p. S395

[3] S. Baragetti, G.M. La Vecchia, A. Terranova: Int. J. Fatigue Vol. 25 (2003), p. 1229

[4] S. Baragetti, G.M. La Vecchia, A. Terranova: Int. J. Fatigue Vol. 27, Iss. 10-12 (2005) p. 1541

[5] S. Baragetti: Int. J. Fatigue, Vol. 29 (2007) p. 1893

[6] S. Baragetti, R. Gerosa, B. Rivolta: Procedia Eng. Vol. 10 (2011) p. 3375

[7] S. Baragetti, L. Lusvarghi, G. Bolelli, F. Tordini: Surf. Coat. Tech. Vol. 203, Iss. 20-21 (2009) p. 3078

[8] R.H. Oskouei, R.N. Ibrahim: Procedia Eng. Vol. 10 (2011) p. 1936

[9] S. Baragetti, L. Lusvarghi, F. Pighetti Mantini, F. Tordini,: Key Eng. Mat. Vol. 348-349 (2007) p. 313

[10] M. Y., Pitanga Costa, M. O. Hilario Cioffi, M. L. Rossignolo Venditti, H. J. C. Voorwald: Procedia Eng. Vol. 2, Issue 1 (2010), p. 1859

[11] Information on www.lafer.eu

[12] International Standard Organization, ISO 1143:1975

[13] R. S., Bellows, S. Muju, T. Nicholas: Int. J. Fatigue, Vol. 21 (1999) p. 687

[14] D. B. Lanning, G. K. Haritos, T. Nicholas Int. J. Fatigue, Vol. 21 (1999) p. S87 
Advances in Fracture and Damage Mechanics XII

10.4028/www.scientific.net/KEM.577-578

Fatigue Behaviour of Thin Coated Al 7075 Alloy with Low Temperature PVD Coatings

10.4028/www.scientific.net/KEM.577-578.221 